\title{
Children Literature Based Program for Developing EFL Primary Pupils' Life Skills and Language Learning Strategies
}

\author{
Safaa M. Abdelhalim ${ }^{1}$ \\ ${ }^{1}$ Faculty of Education, Helwan University, Egypt \\ Correspondence: Safaa M. Abdelhalim, Faculty of Education, Helwan University, Egypt. E-mail: \\ safaa_amk@yahoo.com
}

Received: November 14, 2014 Accepted: December 16, 2014 Online Published: January 20, 2015

doi:10.5539/elt.v8n2p178 URL: http://dx.doi.org/10.5539/elt.v8n2p178

\begin{abstract}
This study examines the effectiveness of a proposed English language program based on integrating two forms of children literature, mainly short stories and songs, in developing the needed life skills and language learning strategies of primary school students. Besides, it emphasized the importance of providing EFL fifth year primary students with activities and opportunities to raise their awareness of their learning, as it helped students understand how to plan, monitor and evaluate their learning. The study targeted ten life skills distributed under four main categories: cognitive, personal, social and linguistic skills. Ninety fifth grade primary students participated in the present study. Five instruments were used: the needed life skills and language learning strategies checklists, a criterion for selecting the stories and songs, the pre/post life skills measures (situation test, questionnaire, oral interpersonal communication test), language learning strategies questionnaire and the students' satisfaction/dissatisfaction questionnaire. The program was taught over a period of two months (two sessions per week). Data collected were analyzed using quantitative and qualitative methodology. Qualitative methods were used to assess students' development over the 8 weeks. Results revealed that life skills and language learning strategies can be taught effectively through the medium of children literature. As a whole, this study contributed to the ESL/EFL field by providing information about the importance of skill building for life at young age and that fundamental changes needed for language instruction. Furthermore, the study presents a detailed teaching strategy for teaching life skills through children literature.
\end{abstract}

Keywords: life skills, Learning strategies, children literature

\section{Introduction}

Education is a process that ready students for the future factual, practical and concrete world as active learners, efficient professionals and as an active and involved citizen. It is much more about thinking skills which involve creative and critical approaches to problem-solving and decision-making. It is also about working skills, including communication and collaboration, as well as the capacity to recognize and employ the potential of new technologies. Recently, the concept of "education for life" has attended much interest among educators from all over the world. This concept is based on Functionalism that illustrates the relationship between schools and society. After schooling students are expected to master a set of life skills to help them function better in various life roles, such as learner, friend, parent, worker, and citizen (Education Commission, 2000).

Kagan (2004) states that nowadays educators are facing a catastrophe, which he referred to as a 'life skills crises'. In his opinion this crisis resulted from the mismatches between what students acquire in the classroom and the demands placed on them outside the classroom. A lot is taught but little is learnt or understood. Knowles (2013, p. 6) assures that educators need to admit, face and address the life skills crisis for the happiness and success of students and the productiveness and success of the society. Whether referred to as life skills or 21 st century skills or soft skills, or social skills Life skills is a broad concept and cannot be defined in one specific category as functioning effectively in society requires a variety of skills (Bailey \& Deen, 2002). Cauthen (2012, p. 22) added that life skills are various and implemented in many venues and the meaning of life skill differs depending on the domain one is using it. Life skills have been defined by the world health organization (WHO) (1993) as "abilities for adaptive and positive behavior that enable individuals to deal effectively with the demands and challenges of everyday life i.e. communication/interpersonal skills, decision-making and critical thinking skills, coping and self-management skills". UNICEF adds that through weaving life skills into the fabric of the educational systems, 
students will be equipped with the necessary tools to cope with challenge and confidently make their own way in the world (Cited in Langcay and Qa'dri, 2013, p. 50). Researchers (Yuen et al., 2007; Shea, 2011) support the view that there is a positive relationship between an individual's competence in life skills and one's emotional adjustment, and that deficits in life skills may lead to offender behavior. Accordingly, Meyers (2001, p. 143) assures that teachers should ready their students with skills in the cognitive, social and emotional domains, as foundations for future life and career skills.

Language teaching experts have argued that life skills can be taught in combination with language skills in language learning contexts. Benne (2013) highlights the fact that learning a language is not limited to learning how to read, write, listen and speak that language, through this process one is supposed to learn a lot about him/herself ; about who he/she is and what his/her values and opinions are. Knowles (2013, p. 7) puts it simple saying "far too often, we've sold our students short. We've given them a decent grasp of English grammar. We've given them a reasonably broad vocabulary. And we've trained them to jump through the various hoops that examining boards put before them. And then we've cast them adrift in the wider world without once considering the kind of flexible, transferable skills they need to really take advantage of the language they've acquired".

O'Dwyer (2013, p. 3) assures that pedagogical leaders in the three educational cycles, primary, secondary, tertiary, need to rethink the pedagogical base of their institutional language teaching practice with a view to reshaping conventional foreign language learning approaches so that the life skill needs of students are met. Englander $(2002$, p. 8) states that classroom language activities that emphasize interaction help students to use language in real contexts. Also, interaction and collaboration among students complement the affective factors in foreign language learning. Self-esteem, empathy, reduced anxiety, and improved attitude and motivation are all fostered when students are engaged in genuine interaction.

Recent trend in EFL teaching highlights the necessity of integrating literature in this process because of its rich potential to provide an authentic model of language use. Scholars and educators of literature are of the opinion that there are three main merits for a literary education program: namely, authenticity; personal growth through presenting a broad spectrum of the ideals and values; and presenting the cultural ideals and social values relevant to the needs and interest of students (Littlewood, 2000; Pardede, 2011). Educational research has shown that students taught language via connections to children's literature become better critical thinkers and problem solvers, and become more able to connect what they learn to personal and real-life experiences.

\section{Context of the Problem}

Despite their appearance in some contexts, life skills instruction and language learning strategies have remained largely in the regality of theory. They are not given enough time or attention while teaching English to fifth year primary stage students. This can be attributed, in the light of the researcher's experience to first, the overloaded curriculum. Second, the prevailing traditional methods of teaching that focus entirely on intellectual and ignore experiential learning. For many students it also has an authoritarian nature and leads students to only extrinsically value education and not intrinsically value learning.

In a pilot study, the author conducted a questionnaire to EFL primary school teachers concerning their opinion about their students' life skills and language learning strategies, how they are reflected in the classroom and outside the classroom and their role in supporting these skills. They reported students' low level in life skills and learning strategies. They added that they have little prior experience with integrating life skills and language learning strategies into language teaching e.g. locating appropriate stories and songs. In addition, they reported that such skills are not an element in the final exam thus it is not focused in their teaching. The researcher also interviewed a sample of fifth primary stage students (20). Participants were asked to define life skills and learning strategies in their own words. Also, they were asked about their usage of such skills and strategies. The results of the interview showed that students are not aware of such skills and rarely use them. Holding another interview with a sample of students' parents, the results confirmed the same idea. There hasn't been any single study in dealing with integrating life skills in language teaching in Egyptian context. From that perspective, there seemed to be a gap in literature. As a result, this study attempted to fill in the gap.

After participating in a professional development workshops at the British council in Egypt for primary educators in 2013, which covered issues on storytelling in teaching English as a foreign language, the author, was motivated to experiment on an unconventional teaching program based on integrating different forms of children literature in developing students' life skills and language learning strategies. 


\subsection{Aim of the Study}

The purpose of this study was to investigate the effectiveness of a proposed English language program based on integration different forms of children literature in developing the needed life skills and language learning strategies of fifth year primary school students. Under this umbrella, a number of related issues necessitated further exploration and investigation: whether pre-preparation of teachers in terms of providing adequate training had any significant effects on students' performance. In addition, the affective domain- students' attitudes was partly investigated.

\subsection{Hypotheses of the Study}

1) There will be statistically significant differences between the two experimental groups and the control group students mean scores on the post-administration of the life skills measures (the situation test of the cognitive domain, the interpersonal oral communication test of the linguistic domain, and the questionnaire of the personal and social domains) and the language learning strategies questionnaire in favor of the two experimental groups.

2) There is a statistically significant difference between the first experimental group(whose teachers received no pre-training), and the second experimental group(whose teachers received pre-training) students' mean scores on the post administrations of the life skills measures and the language learning strategies questionnaire in favor of the second experimental group.

3) There will be a statistically significant difference between the first experimental group (whose teachers received no pre-training) students' mean scores on the pre-and post-administrations of the life skills measures and the language learning strategies questionnaire in favor of the post-testing scores.

4) There will be a statistically significant difference between the second experimental group (whose teachers received pre-training) students' mean scores on the pre-and post-administrations of the life skills measures and the language learning strategies questionnaire in favor of the post-testing scores.

5) There is a positive correlation between developing life skills and developing language learning strategies for the experimental groups' students.

6) There will be a degree of satisfaction among the students of the experimental groups after joining the proposed program.

\subsection{Significance of the Study}

The present study may provide insight, vision, and inspiration to the following categories:

- TEFL pedagogical leaders in the three educational cycles, primary, secondary, tertiary, directing their attention to rethink the pedagogical base of their institutional language teaching practice with a view to reshaping conventional foreign language learning approaches so that the life skill needs of students are met.

- Supervisors of English language teaching as it supplements a study involving language, literature, life skills, curricula, methodology, and assessment- the ultimate goal of which is the upgrading of the teaching-learning process to the utmost.

- EFL teachers, it offers a genuine example to imitate when teaching both language and literature, in addition to providing ready-made material which can be employed for activating English language clubs, which most find it highly challenging to prepare for.

\section{Review of Literature}

\subsection{Characteristics and Learning Styles of Young Learners}

Early education plays a crucial role in students' future success. Thus, providing high quality learning is an unavoidable issue that arises in the primary stage classrooms. According to Piaget (1951) students at the "concrete operational stage" (ages 7-11), which is the focus of this study, profit from concrete, practical, active learning experiences that bridge the gap between abstract concepts and the hands on real world. Through exploration and play, children learn about their world. According to Selman's theory (1980 cited in Pires, 2011) on interpersonal understanding children at ages 7-12, can mentally put themselves in someone else's place and have a self-reflective view of their own thoughts and actions. Also, friendship has crucial role, child is able to take into consideration the other's perspective, addressing both self and friend's needs. Children at this growth stage are known for their preference for adventure and heroines, searching for facts, loving competition thus search for team work to compete with other teams. 


\subsection{Life Skills}

\subsubsection{Evolving Life Skill Definitions}

Cauthen (2012, p. 22) indicated that assigning a clear and concise definition for life skills is a crucial step in designing a life skills learning program, in order to assess the growth and development of participants through the process of learning life skills. According to the United Nations Children's Fund (UNICEF, 2009) life skills refers to "a behavior change or behavior development approach designed to address a balance of three areas: knowledge, attitudes and skills". The United Nations Educational, Scientific and Cultural Organization (UNESCO, 2009) defined them as "a group of cognitive, personal and interpersonal abilities that help people make informed decision, solve problems, think critically and creatively, communicate effectively, build healthy relationships, empathize with others, and cope with and manage their lives in a healthy and productive manner".

Due to the varying definitions mentioned above and the need for a concise definition for the purpose of this study, life skills are defined as: a group of competencies, classified in four domains: cognitive, personal, social, and linguistic, that enable primary stage students to adapt and adjust to everyday life situations, live to their full potentials and function properly in society"

\subsubsection{Life Skills Classifications}

There is no one certain list of life skills; they alter in importance and priority according to certain life situations, culture, age, position. Moreover, UNICEF assures that life skills are a synthesis. There are many life skills that used simultaneously in action e.g. problem solving and decision-making often involves critical thinking, values clarification and team work.

Reviewing many different initiatives for classifying life skills, it becomes clear that there are three dominant types: first, categorization according to the three personal characteristics: cognitive, social and affective. Second, categorization according to the encountered life situations and the necessary skills to pass them successfully. Finally, categorization according to life roles that one held throughout his life stages as learner, worker, parent, citizen, friend.

UNICEF website on life skills provides three overarching categories within which the skills are placed: communication and interpersonal skills which incorporates interpersonal communication skills, negotiation and refusal skills, empathy, and cooperation and teamwork; decision-making and critical thinking skills that includes problem-solving and thinking critically and ; coping and self-management skills encompasses increasing one's internal locus of control, skills for managing feelings, and handling stress (UNICEF, 2011). The Iowa State University Extension programs (ISUE) (2012) presents the targeting life skills (TLS) model. In this model, categories of life skills are identified and divided on the basis of the familiar four H's from the 4-H Clover that represent Head, Heart, Hands, and Health". These four "H's" are conforming with the four aspects of a psychologically mature person who is a problem solver (head), empathic (heart), acts on democratic values (hands), and is autonomous and self-directed (health).

\subsubsection{Life Skills within EFL Classroom}

Gregersen (2013, p. 16) declares that the notion that learners can develop language proficiency while receiving instruction in life skills is supported by current research that advocates learning a language while seeking other goals e.g. content based instruction, task-based instruction, and in participatory approaches.

O'dwyer (2013, p. 6) states that incorporating life skills into language education might require what Senge (1990) calls 'Metanoia', a change in mental set of the language instructor; starting to have a broader educational aim within the educational and institutional context rather than just focusing only on developing the four language skills. Accordingly, A prerequisite for language instructors would be for them to see themselves as educators who willingly set broader educational goals as an integral part of their commitment to a achieving a broadly defined curriculum. O'dwyer adds that such a shift in emphasis also requires a major rethink from the educational institution itself as well as the instructor. As life skills are transferrable skills across disciplines and are applicable to a range of contexts which may have nothing to do with language learning, they need to be defined at an institutional level and should be represented as a commitment for attaining the overall mission and goals of an educational institution. O'dwyer (2013, p. 6) recommends that curriculum objectives that cover Life skills include:

- The ability to make choices based on a critical analysis of specific contexts, to seek information, to weigh up options, to compare them and choose from a number of alternatives. 
- The ability to reflect on the impact of the skill on the environment, on the community, and on the well-being of all for the future (the social consequences of actions).

- The ability to apply critical judgments in the light of available and often conflicting evidence and make impartial decisions for the benefit of the community.

\subsubsection{Children Literature and Life Skills (Benefits Gained)}

Literature and life meet in the field of human relationships. What characterizes quality literature also characterizes deliberate life. children's literature represents an educational mediator, which provides the opportunity for children to learn more about themselves, their environment, and get answers to their questions and inquiries, help their curiosity, imagination, discovery, accepting new experiences, and achieving self-confidence (Al-Alami, 2003, p. 2). Pires (20111) highlights that children literature is an important element in primary students' education as it establishes a connection between school and out of school contexts. He adds that children literature supports school's social responsibility through its natural role in the transmission of values and building identity.

Reese (2002) states that through incorporating literature in classroom teaching teachers can launch their students on a voyage of discovery, exploring new ways of seeing and being as well as clarifying their own world view. According to Vygotsky (1978) socio-cultural theory through interpersonal dialogue and social interactions during story-telling classes and shared activities teacher can scaffold students to reflective intrapersonal thought, a stage in which they review and reflect on their personal statue concerning the learned values in the story.

Santora (2006) believes that through stimulating children's imagination, literature can be seen as a mirror in which children can see themselves reflected, and also a window through which they can explore and gain better understanding the world around. De Naples (2002) studying literature not only helps the study of language but it helps the student to think in this language. Through characters analysis, theme discussion, role playing activities, literary works helps students develop their way of thinking and build up a personal point of view based upon the reading and understanding of the work of art.

Zafeiriadou (2001) presents a pedagogic approach to the teaching of literature based upon learner-centeredness approaches. The overall philosophy of this pedagogic approach can be summarized as follows:

- Literary texts should appeal to students' interests, concerns and age.

- The teaching of literature in an EFL context should aim to elicit the students' responses to the text, and to guide them to a personal discovery.

- Literary texts should be approached as a resource and a fruitful opportunity for students' education and their personal growth.

- A new role and responsibilities for the teacher should be established. The teacher is not anymore the unquestionable authority in the language classroom

- The exploration of texts comes closer to the students' personal experiences and to what relates to their life through teaching techniques and practices divided into pre-reading, while reading and after reading activities.

Despite its benefits for students, some objections are always raised against the use of literature in public schools due to overcrowded classes, overloaded syllabus and limited time- some problems commonly met in primary to high public schools in almost all developing countries. First, the deviated and figurative language of poetry necessitates very long time to grasp. Second, the length of novel will make it difficult for such classes to finish. Finally, drama can be used in classes, but it will be difficult to act out a play in crowded classes within limited course hours. Considering these objections, it is obvious that among literary forms, short-story and songs seems to be the most suitable types to use in these schools.

Ellis (2002, cited in Hana, 2010, pp. 5-6) and Pardede (2011, p. 16) compile some reasons for using storytelling. Among them: introducing new language in context thus facilitates language learning, Sharing experiences, providing opportunities for self-expression, fostering the development of self-confidence, and self-esteem, stimulating interest in reading for pleasure.

Many educators have repeatedly written on the benefits of songs in an ELT setting (Obiozor, 2010; Patel \& Laud, 2007). These benefits can be summarized under two factors. First, linguistic factors: enlarge the vocabulary background, develop listening and speaking skills, introduce and familiarize students with the target language culture, improve pronunciation, teach various language functions. Second, affective factors: add fun to learning, motivate students to participate even shy ones, help teachers get closer to their students, stimulate students' interest in the new language, and create a lively atmosphere in the language classroom. 


\subsection{Life Skills \& Language Learning Strategies Intertwining Relation}

Gregersen (2013, p. 14) declared that the goals for life skills and learning strategies are closely intertwined. In essence, life skills education aims at offering strategies to students so that they make true and wise choices that contribute to a meaningful life (www.unicef.org). Dornyei (2005, p. 169 cited in Gregersen, p. 14) suggests the following learning strategies four categories that reflect life skills education:

1) Social strategies: These mirror the communication and interpersonal life skills. As language learners ask verification questions, request clarification, ask for help in doing a language task (Oxford, 2003), they will also be practicing the essential interpersonal communication life skills i.e. verbal and nonverbal communication, active listening, expressing feelings and giving feedback, negotiating and managing conflict, building empathy and cooperating with others.

2) Cognitive strategies: when language learners use these strategies (including: reasoning, analysis, note-taking, summarizing, synthesizing) to manipulate the language materials in direct ways (Oxford, 2003), they will also be developing the cognitive life skills of information gathering, evaluating future consequences of present actions, determining alternative solutions to problems, and analyzing the influence of values and attitudes.

3) Metacognitive strategies i.e. analyzing, monitoring, evaluating, planning, and organizing the learning process; and affective strategies which involve taking control of the emotional/affective conditions (Oxford, 2003) reflect the personal life skills of coping and self-management as they build their self-esteem and self-confidence (UNICEF.org).

\section{Method}

\subsection{Design of the Study}

The present study followed the pre-posttest quasi experimental control design supported by qualitative and quantitative data for examining the effectiveness of the proposed children literature based program on developing the life skills and language learning strategies of primary five stage students. Three classes were chosen randomly from fifth grade primary stage at three experimental language schools and were assigned into three groups: experimental group one, whose teachers received no pre-training, experimental group two, whose teachers received pre training, and control group who were not exposed to any treatment, yet set for the tests conducted and administered for study purposes.

\subsection{Variables of the Study}

- Independent variable: the proposed children literature based program.

- Dependent variables: developing primary five students' life skills and language learning strategies.

\subsection{Delimitations of the Study}

- A sample of fifth primary grade students in three experimental language schools and four EFL primary school teachers.

- A 8-weeks duration of implementation (the second semester of the school year 2013-2014).

- Using the English language club held for two hours weekly as a setting for implementation.

- Developing the eleven main life skills and ten basic language learning strategies shown in the final version of the two checklists in appendices.

\subsection{Sample of the Study}

Ninety (90) fifth grade primary pupils participated in the present study. This sample was selected from three different experimental language schools in El-Maadi and in El-Doki Educational directorates. Also, four EFL primary school female teachers (38-40 years old) participated in the study (two teachers in each school). The four teachers were graduated from Faculty of Education, English section. Their teaching experience ranged from 10 to 12 years. Each of the experimental groups was taught by two teachers, each teacher taught 8 lessons.

\subsection{Instruments of the Study}

\subsubsection{The Life Skills Checklist}

This checklist aimed to determine the most necessary life skills to be developed for fifth primary stage students. The checklist included 11 main skills distributed under four main categories: cognitive ( 3 skills), personal ( 3 skills), social (3 skills) and linguistic ( 2 skills). Sources of the checklist: the life skills included in the checklist in its primary form were determined through reviewing: previous literature and related studies concerned with developing life skills e.g Mass (2006), Boleman (2004), Loeser (2004), Fox (2003), Bender (2002), etc (see 
appendix 1).

\subsubsection{The Learning Strategies Checklist}

This checklist was employed to determine the most needed learning strategies to be mastered by fifth primary stage students. The checklist composed of four cognitive strategies, three metacognitive strategies and three social affective strategies.

\subsubsection{The Criterion of Choosing the Short Stories and Songs Used in the Program}

This criterion aimed at Identifying the basics that should be presented in each children literature form (short story and song) of the proposed program content in light of its: structure and design, suitability to students needs and attitudes, its suitability for developing some life skills of primary stage students. Selected literary works should correspond with the teaching/learning objectives of the proposed program: Include some positive values, developing of the main character behaviors, characters overcome critical situations and solve problems using scientific thinking steps and good behaving.

\subsubsection{Life Skills Measures}

a) The situation test:

This test aimed to assess the students' level of proficiency in the identified life cognitive skills before and after starting the experiment. The pre/posttest consisted of 3 Simple clear and accurate daily life situations that suit the participants. In each situation students are asked two questions related to the given situation. Students have to apply the cognitive life skills (critical/creative thinking, problem solving, decision making) they have practiced during the program in order to answer these questions. Students are expected to give three possible answers for each question.

- Test validity: To measure the validity, the first version of the test consisting of 6 situations, one question each, was submitted to seven TEFL professors and lectures to evaluate the situations and related questions in terms of appropriateness and skills measured. Moreover, the jury members were asked to evaluate the test as a whole in terms of: a) number of questions and appropriateness to the functions measured, b) suitability of the questions to fifth year primary experimental language students linguistic level and c) suitability of the test to measure the intended skills. The panel of the jury suggested some modifications as follows:

- Making the test shorter by reducing the number of the situations to 3 situations instead of 6 .

- Adding another question to each situation so each situation has two questions so each situation tests more than one skill as daily situations are.

- Modifying the style of writing to suit students' linguistic level.

- The researcher followed these modifications and resubmitted it to the jury who approved its validity.

- Test reliability: The degree of inter-rater reliability was established by correlating the scores obtained by students from rater (A) with those from rater (B). It was assessed through correlation coefficient. It was found that the estimated correlation coefficient ( 0.98$)$ was significant at 0.01 . This shows reliability of the test.

b) The interpersonal oral communication test:

This pre-posttest was intended to measure the linguistic category of the life skills represented in some interpersonal oral communication skills (effective listening and speaking) specified in the life skills checklist. The assessment rubric helped in quantifying the identified interpersonal oral communication skills against its criteria and consequently realizing the test purpose. The test had four main parts.

Part A: Students share in a free interview with the researcher (exchanging personal information)

Part B: Students, in pairs, select a couple of pictures and compare between them.

Part C: Students, in pairs, select a cartoon picture from a given album then prepare and practice the conversation that might take place between the cartoon characters in the picture.

Part D: each student receives a band of pictures and he/she will be asked to put them in logical order telling a story then tell it expressively.

The scoring rubric of the test consisted of six domains: intonation and pronunciation, choice of words and vocabulary, grammar, effective listening, communication (fluency of ideas and speech) and nonverbal domain. Each domain had four levels (from 1 to 4 ) the four levels indicated the students' marks on each domain.

- Test validity: an initial version of the test was submitted to a jury of experts in the field of EFL teaching and 
testing. The jury members were asked to determine whether the items of the test represent what are supposed to represent and whether they are linguistically and scientifically appropriate. Also, they were asked to give their opinions about the test items with regard to using pictures in the test and the appropriateness of the test for the level of students. The jury approved the test items and appreciated using pictures in the exam. They suggested increasing the number of pictures in order to give students the chance to choose from. They also expressed their approval of the form and content of the test. Modifications were made according to the opinion of the jury members until the test was written in its final version.

- Test reliability: The correlation coefficient was calculated by using the split-halves method (Harrison, 1986, p. 12 ) and it was found to be 0.86 . The reliability coefficient was calculated by using the Spearman-Brown formula (McCall, 1975, p. 140) and it was 0.91.

c) Personal and social life skills questionnaire:

This questionnaire aimed to measure the personal and social domains of the life skills before and after the experiment. The questionnaire consisted of 22 items ( 13 items for the personal skills and 9 items for the social skills). Students were asked to rate their personal and social skills and abilities. The answers were recorded on 5-point likert scale (always, often, sometimes, rarely, almost never).

- Validity: to insure the validity of the questionnaire, an initial draft of the questionnaire (25 items) was submitted to jury members specialized in ELT to examine the structure, logical flow of the questionnaire, the wording, clarity, length and the order of the items. The researcher then made some modifications based on the comments of the experts. For instance, items with semantic ambiguity were clarified or deleted, and items recommended by the jury were added.

- Reliability: a test retest procedure was conducted to establish the reliability of the questionnaire. The correlation coefficient was 0.89 which means that the questionnaire was reliable.

\subsubsection{Language Learning Strategies Questionnaire}

This questionnaire aimed to assess the use of the language learning strategies of fifth primary stage students before and after the experiment. The questionnaire consisted of ten statements. The questionnaire had undergone a pilot test before being finally administered. Respondents were asked to use a 3-point rating scale format $(3=$ always, 2 = sometimes, 1 = rarely) to describe how much they agreed with each statement.

- Validity of the questionnaire: the questionnaire was handed to the jury members specialized in ELT. Jury members were asked to rate each statement with a score ranging from 1 to $5(1$ stands for the lowest valid statement and 5 for the most valid one) and to write their suggestions and comments. Also, the mean scores of the jury members determine if the questionnaire did measure the levels of the language learning strategies that the participants use. Some modifications were suggested by the jury members. For example long statements were divided into two statements; some statements were deleted others were added. It was resubmitted and jury approved its validity.

- Reliability: a test-retest procedure was conducted to establish the reliability of the questionnaire. The correlation coefficient was 0.93 which mean that the questionnaire was reliable at the level of 0.01 .

\subsubsection{Students' Feedback Questionnaire}

In order to collect data about how far the children in the experimental groups were motivated and satisfied with the content and activities of the program, a satisfaction questionnaire was designed. It consisted of eight statements, in front of each statement there are two kinds of faces; smiley one and frown one, the pupils had to tackle the face that expresses his/her opinion whether s/he is satisfied with this statement or not (see appendix H).

- Validity of the questionnaire: the questionnaire was handed to the jury members to rate each statement with a score ranging from 1 to 5 ( 1 stands for the lowest valid statement and 5 for the most valid one) and to write their suggestions and comments. Also, the mean scores of the jury members determine if the questionnaire did measure the levels of the language learning strategies that the participants use. Some modifications were suggested by the jury members. It was resubmitted and jury approved its validity.

- Reliability: A test-retest procedure was conducted to establish the reliability of the questionnaire. The correlation coefficient was 0.94 which mean that the questionnaire was reliable at the level of 0.01 .

\subsubsection{Teacher's Reflection Log}

For qualitative data requirements and to get more insights on teacher's practices and challenges and successes 
they met during study implementation, they were asked to keep self- reflection log where they fully described their practices inside the classroom After the administration of each lesson.

\subsubsection{Students' Learning Logs}

It is a record of the students' experiences with the use of the life skills and language learning strategies inside and outside the classroom, including the when and the where of skills use and why certain experiences were successful and others were not.

\subsection{The Proposed Program}

\subsubsection{Aim of the Program}

The program aims at developing some life skills and language learning strategies for the fifth year of primary stage experimental language school students via using children literature based program.

\subsubsection{Duration of the Program}

The program was taught in a period of 8 weeks (two lessons per week-one hour each) during the second term of the school year 2013/2014. It consisted of four units (four lessons each). Each lesson was taught in one session the first session was an introductory session.

\subsubsection{Content of the Program}

The program consisted of two parts, the first part is teacher's training and it consisted of three sessions (60 minutes each) to raise the second experimental group teacher's awareness of the importance of children literature in teaching foreign language classroom and how to use it effectively in developing students' life skills and language learning strategies. The second part included a students' booklet and a teachers' guide. A user-friendly teacher's guide was prepared by the researcher and given to the four teachers who participated in the study. The students' booklet, entitled 'the story of life skills' consisted of 4 units, 4 lessons each. Each lesson contains a short story and a song focusing on certain theme of life skills followed by interactive activities that help students to practice these skills and experience a new strategy of thinking about language and language learning. Analyzing 40 short stories and 30 songs from different genres and analyzing each in the light of a checklist built according to the items of the criterion of selecting children literature forms to EFL fifth primary grade students, the researcher reached a list of 16 short stories and 16 songs. Then the researcher classified them according to the four main themes of life skills: cognitive, personal, social, and linguistic. Each unit covers one theme.

4.6.4 Teaching Methods: According to Teacher's Guide Instruction, Each Lesson Was Supposed to Be Taught According to the Phases Underneath

1) Pre-reading activities (Defining and Promoting the targeted Life Skill):

- Introduce students to the theme of the lesson to activate their prior knowledge and warming them up and preparing them for the new activities,

- Defining the targeted life skill: how it is crucial in influencing a targeted behavior or life situation; what will the student be able to do if they master this skill?

- Relate the topic to the students' experiences in daily lives through Generating positive and negative examples of how the targeted skill is applied,

- Encourage students to be active participants in the class discussions.

- Motivate and assist the students to approach each lesson story and song in a meaningful manner through pre teaching new vocabulary and structures.

- Formulate pre-questions and predict the upcoming events.

2) During reading activities (Skill Acquisition and Performance): they include what the students do themselves while accomplishing a learning task and what the teacher does to assist them. They include:

- Skimming to verify predictions and pre questions,

- Generating questions on the part of the students by the teacher's help.

- Reading in action activities e.g.

- Scanning: As you read find out...

- Taking notes: Keeping track...

- Close study: focus on character... 
- Reader's response: How do you view ...? Justify your answer, what do you think would happen next?

- Providing opportunities to observe Life skills being applied effectively referring to the story/song.

- Providing opportunities for practicing the targeted life skill with coaching and feedback.

- Providing feedback and recommendations for corrective action.

3) Post-reading activities (Fostering Skill Maintenance/Generalization): These activities involve students in various kinds of synthesizing, analyzing and applying. They include:

- Answering questions measuring literal and critical comprehension.

- Students describe the characters by completing a framework provided by the teacher.

- Groups discuss specific questions relating to particular character's behaviors.

- Creative drama- referring to role playing and improvisation which aim at expanding the boundaries of experiences for students.

- Telling personal stories about the same life skill.

4) Evaluation: This phase focused on evaluating the pupils' life skills and language learning strategies in a kind of formative evaluation. During this evaluation students' parents were involved with the teachers in supporting learned life skills and learning strategies. In class teachers assigned different questions after each activity in order to know if the students fully understand the aims behind activities presented to them. After class time there were activities at the end of each lesson that students should complete at home with their parents support. These activities included: retelling stories to their families in their own words, singing songs, writing comments on what they have learnt in each lesson, in their learning logs, and drawing a portrait of each of the main characters representing what they think each really is. Moreover, in order to foster self - evaluation and skill adjustment: students were asked to use a self-evaluation chart to reflect on their progress in life skills and language learning strategies.

\subsubsection{Validity of the Program: Experts Opinion}

The program was reviewed by experts in generic or specific life skills training or child development. Comments on format included suggestions regarding tighter copy editing, inclusion of more pictures. Comments on contents were:

- Reduce the numbers of activities, and avoid overlap in themes and activities

- Reformulate objectives and outcome of the activities, to make them more clearly relevant to the activity

- Highlight life skills, which are the central aspect of the program, in the discussion and summing up of activities.

\section{Results and Data Analysis}

\subsection{Quantitative Data}

The results of this study are presented by relating them to the hypotheses of the study. Data collected were analyzed by the Statistical Package of the Social Sciences (SPSS) 16.0. Pre-test results showed that that there is no significant difference among the three groups on the pre-tests and the three groups were equivalent before applying the program. Thus any progress achieved by the experimental groups was directly due to the suggested program

5.1.1 Hypotheses Concerned with Comparing between the Experimental Groups and the Control Group Means Scores on the Posttests (The First and Second Hypotheses)

To confirm the validity of these hypotheses, the F-test was administered to compare the mean scores of the three groups on the posttests. Relevant data to this hypothesis are provided in table (1) and (2). 
Table 1. The pre-test and post-test means and standard deviations for students of the three groups in the life skills measures and the language learning strategies questionnaire

\begin{tabular}{lllllll}
\hline \multirow{2}{*}{ Variable } & \multirow{2}{*}{ Group } & \multicolumn{3}{l}{ Pre-test } & \multicolumn{3}{l}{ Post-test } \\
\cline { 4 - 7 } & & Exp1 & 7.68 & $(0.98)$ & 15.06 & $(1.50)$ \\
& \multirow{6}{*}{ Situation test } & Exp2 & 7.45 & $(1.03)$ & 15.77 & $(1.77)$ \\
& & Control & 7.77 & $(0.92)$ & 10.29 & $(1.16)$ \\
\multirow{4}{*}{ Life skillss } & Oral & Exp1 & 10.13 & $(1.84)$ & 19.81 & $(1.47)$ \\
& \multirow{4}{*}{ communication } & Exp2 & 10.45 & $(1.90)$ & 21.90 & $(1.72)$ \\
& & Control & 10.48 & $(2.05)$ & 12.52 & $(1.96)$ \\
& \multirow{4}{*}{ Personal \& social } & Exp1 & 65.39 & $(6.27)$ & 95.52 & $(4.18)$ \\
& skills & Exp2 & 65.71 & $(6.74)$ & 101.3 & $(5.03)$ \\
& & Control & 66.90 & $(8.18)$ & 69.23 & $(7.88)$ \\
\hline \multirow{6}{*}{ Language learning strategies } & Exp1 & 12.26 & $(1.95)$ & 24.06 & $(2.86)$ \\
& & Exp2 & 12.77 & $(2.06)$ & 27.39 & $(2.08)$ \\
& & Control & 12.55 & $(2.00)$ & 15.26 & $(1.32)$ \\
\hline
\end{tabular}

Table 2. One-way ANOVA test results comparing the post-test means for students of the three groups in the life skills measures and the language learning strategies questionnaire

\begin{tabular}{|c|c|c|c|c|c|c|c|c|}
\hline Variable & & $\begin{array}{l}\text { Source } \\
\text { variance }\end{array}$ & $\begin{array}{l}\text { Sums of } \\
\text { squares }\end{array}$ & $d f$ & $\begin{array}{l}\text { Mean } \\
\text { square }\end{array}$ & $\mathrm{F}$ & $\begin{array}{l}\text { Sig. } \\
\text { level }\end{array}$ & $\begin{array}{l}\text { Effect } \\
\text { size }\left(\eta^{2}\right)\end{array}$ \\
\hline \multirow{9}{*}{ Life skills } & \multirow{3}{*}{ Situation test } & Between groups & 551.484 & 2 & 275.742 & 123.052 & .0001 & .73 \\
\hline & & Within groups & 201.677 & 90 & 2.241 & & & \\
\hline & & Total & 753.161 & 92 & & & & \\
\hline & \multirow{3}{*}{$\begin{array}{l}\text { Oral } \\
\text { communication }\end{array}$} & Between groups & 1505.183 & 2 & 752.591 & 251.525 & .0001 & .85 \\
\hline & & Within groups & 269.290 & 90 & 2.992 & & & \\
\hline & & Total & 1774.473 & 92 & & & & \\
\hline & \multirow{3}{*}{$\begin{array}{l}\text { Personal } \\
\text { social skills }\end{array}$} & Between groups & 18085.57 & 2 & 9042.79 & 258.933 & .0001 & .85 \\
\hline & & Within groups & 3143.097 & 90 & 34.923 & & & \\
\hline & & Total & 21228.67 & 92 & & & & \\
\hline \multirow{3}{*}{\multicolumn{2}{|c|}{ Language learning strategies }} & Between groups & 2435.634 & 2 & 1217.82 & 256.586 & .0001 & .85 \\
\hline & & Within groups & 427.161 & 90 & 4.746 & & & \\
\hline & & Total & 2862.796 & 92 & & & & \\
\hline
\end{tabular}

Table 1 reveals that there is a statistically significant difference between the two Experimental groups, and the control group students' mean scores on the post-administration of the three life skills measures and the language learning strategies questionnaire at the level of (0.01), in favor of the experimental groups, thus the first hypothesis of the present study was verified. Moreover, in order to make sure that the results obtained from the ANOVA test are reliable and to measure the effectiveness of the proposed program, the effect size of the proposed program on students' life skills and language learning strategies were calculated. As shown in Table 2, the proposed program had a large effect on experimental groups students' life skills and language learning strategies on the posttest as compared to that of the control group students. 
Table 3. Tukey post-hoc multiple comparisons test for students of the three groups in the post-test of life skills measures and the language learning strategies questionnaire

\begin{tabular}{|c|c|c|c|c|c|}
\hline Variable & & Groups & Mean difference & Sig. level & \\
\hline \multirow{9}{*}{ Life skills } & \multirow{3}{*}{ Situation test } & Exp1 \& Exp2 & -.710 & Not sig. & - \\
\hline & & Exp1 \& Control & $4.774 *$ & .05 & Exp1 \\
\hline & & Exp2 \& Control & $5.484 *$ & .05 & Exp2 \\
\hline & \multirow{3}{*}{$\begin{array}{l}\text { Oral } \\
\text { communication }\end{array}$} & Exp1 \& Exp2 & $-2.097 *$ & .05 & Exp2 \\
\hline & & Exp1 \& Control & $7.290^{*}$ & .05 & Exp1 \\
\hline & & Exp2 \& Control & $9.387^{*}$ & .05 & Exp2 \\
\hline & \multirow{3}{*}{$\begin{array}{l}\text { Personal \& social } \\
\text { skills }\end{array}$} & Exp1 \& Exp2 & $-5.742 *$ & .05 & Exp2 \\
\hline & & Exp1 \& Control & $26.290^{*}$ & .05 & Exp1 \\
\hline & & Exp2 \& Control & $32.032 *$ & .05 & Exp2 \\
\hline \multirow{3}{*}{\multicolumn{2}{|c|}{ Language learning strategies }} & Exp1 \& Exp2 & $-3.323^{*}$ & .05 & Exp2 \\
\hline & & Exp1 \& Control & $8.806^{*}$ & .05 & Exp1 \\
\hline & & Exp2 \& Control & $12.129^{*}$ & .05 & Exp2 \\
\hline
\end{tabular}

As for the second hypothesis, Table 3 shows that:

1) There were no statistically significant difference between the first experimental group and the second experimental group students' mean scores on the post administration of the cognitive life skills situation test,

2) there were statistically significant differences between the first experimental group and the second experimental group pupils' mean scores on post administrations of the language learning strategies questionnaires and two of the life skills measures, namely, the personal and social questionnaire and the oral interpersonal communication test in favor of the second experimental group, thus the second hypothesis of the present study is partially verified.

5.1.2 Hypotheses Focusing on Comparing between the Experimental Groups Mean Scores before and after the Treatment (The Third and the Fourth Hypotheses)

To determine the relative extent of change fostered by the implementation of the proposed program from the pre-test to the post-test for the two experimental groups, t-test for paired samples was used. This t-test aimed at comparing the mean scores of the experimental groups on the pre-test and the post-test in life skills measures and language learning strategies.

Table 4. T-test results comparing the pre-test VS post-test means for students of the three groups in the life skills measures and the language learning strategies questionnaire $(\mathrm{N}=31, \mathrm{df}=30)$

\begin{tabular}{|c|c|c|c|c|c|c|c|c|c|c|}
\hline \multirow{2}{*}{ Variable } & & \multirow{2}{*}{ Group } & \multicolumn{2}{|c|}{ Pre-Test } & \multicolumn{2}{|c|}{ Post-Test } & \multirow{2}{*}{ MD } & \multirow{2}{*}{ T value } & \multirow{2}{*}{$\begin{array}{l}\text { Sig } \\
\text { level }\end{array}$} & \multirow{2}{*}{$\begin{array}{l}\text { Effect } \\
\text { size }\left(\eta^{2}\right)\end{array}$} \\
\hline & & & $\mathrm{M}$ & (SD) & M & $(\mathrm{SD})$ & & & & \\
\hline \multirow{6}{*}{ Life skills } & \multirow{2}{*}{ Situation test } & Exp1 & 7.68 & $(0.98)$ & 15.06 & $(1.50)$ & 7.387 & 51.206 & .0001 & .99 \\
\hline & & Exp2 & 7.45 & $(1.03)$ & 15.77 & $(1.77)$ & 8.323 & 39.747 & .0001 & .98 \\
\hline & \multirow{2}{*}{$\begin{array}{l}\text { Oral } \\
\text { communication }\end{array}$} & Exp1 & 10.13 & $(1.84)$ & 19.81 & (1.47) & 9.677 & 37.249 & .0001 & .98 \\
\hline & & Exp2 & 10.45 & $(1.90)$ & 21.90 & $(1.72)$ & 11.452 & 41.837 & .0001 & .98 \\
\hline & \multirow{2}{*}{$\begin{array}{l}\text { Personal \& social } \\
\text { skills }\end{array}$} & Exp1 & 65.39 & $(6.27)$ & 95.52 & $(4.18)$ & 30.129 & 33.166 & .0001 & .97 \\
\hline & & Exp2 & 65.71 & $(6.74)$ & 101.3 & $(5.03)$ & 35.548 & 41.829 & .0001 & .98 \\
\hline \multirow{2}{*}{\multicolumn{2}{|c|}{ Language learning strategies }} & Exp1 & 12.26 & $(1.95)$ & 24.06 & $(2.86)$ & 11.806 & 28.043 & .0001 & .96 \\
\hline & & Exp2 & 12.77 & $(2.06)$ & 27.39 & $(2.08)$ & 14.613 & 38.304 & .0001 & .98 \\
\hline
\end{tabular}


Table 4 indicates that there were statistically significant difference in life skills and language learning strategies between the mean scores of the two experimental groups on the pre- and post-tests in favor of the post-test scores Moreover the program had a large effect on the experimental groups students' life skills and language learning strategies on the post-tests as compared to their performance on the pre-tests.

5.1.3 The Fifth Hypothesis: Investigating the Correlation between Developing Life Skills and Language Learning Strategies for the Experimental Groups' Students

Table 5. Correlations matrix between the developed performance of life skills and the language learning strategies for students of the two experimental groups

\begin{tabular}{|c|c|c|c|c|c|}
\hline \multicolumn{2}{|l|}{ Variable } & Situation test & $\begin{array}{l}\text { Oral } \\
\text { communication }\end{array}$ & $\begin{array}{l}\text { Personal \& social } \\
\text { skills }\end{array}$ & $\begin{array}{l}\text { Language learning } \\
\text { strategies }\end{array}$ \\
\hline \multirow{3}{*}{ Life skills } & Situation test & --- & & & \\
\hline & $\begin{array}{l}\text { Oral } \\
\text { communication }\end{array}$ & $.468 * *\left(\mathrm{R}^{2}=.22\right)$ & --- & & \\
\hline & $\begin{array}{l}\text { Personal \& social } \\
\text { skills }\end{array}$ & $.336 * *\left(\mathrm{R}^{2}=.11\right)$ & $.482 * *\left(\mathrm{R}^{2}=.23\right)$ & --- & \\
\hline \multicolumn{2}{|c|}{ Language learning strategies } & .175 & .122 & $.262 *\left(\mathrm{R}^{2}=.07\right)$ & --- \\
\hline
\end{tabular}

(**) Correlation is significant at the 0.01 level $(*)$ Correlation is significant at the 0.05 level.

Table 5 shows that there is a positive correlation between the percentages of developed scores between the life skills and the language learning strategies. This correlation was medium among the life skills and small between life skills and learning strategies.

\subsubsection{Results of Students' Feedback Questionnaire}

Table 6. Percentage of the experimental groups' responses to the students' feedback questionnaire

\begin{tabular}{llll}
\hline $\mathrm{N}$ & Statements & Exp-group 1 & Exp-group 2 \\
\hline 1 & $\begin{array}{l}\text { Did you enjoyed practicing life skills and language learning strategies through } \\
\text { using stories and poems/songs in class }\end{array}$ & 100 \\
2 & $\begin{array}{l}\text { Do you like to keep practicing life skills and language learning strategies } \\
\text { through stories and poems/songs based activities in your class next year }\end{array}$ & 89 \\
3 & Were the chosen stories and poems/songs lovely & 99 \\
4 & $\begin{array}{l}\text { Was it easy for you to understand the relation between the main theme of each } 75 \\
\text { story and poem/song and the targeted life skill }\end{array}$ & 77 \\
5 & $\begin{array}{l}\text { Was the time enough for practicing the life skills and language learning } 66 \\
\text { strategies in class }\end{array}$ \\
6 & $\begin{array}{l}\text { Was it easy for you to share in the life skills and language learning strategies } 89 \\
\text { activities }\end{array}$ & 89 \\
7 & $\begin{array}{l}\text { Can you tell some of the life skills and language learning strategies you } 88 \\
\text { practiced in class? }\end{array}$ & 87 \\
8 & Do you think you learn better with this program? & 100 \\
\hline
\end{tabular}

Table (6) reveals percentages of the experimental groups' responses to the students' feedback questionnaire in the two schools. There is an indication that the majority of students enjoyed stories and songs in the program (100\%). All students $(100 \%)$ in the two groups said that they learnt better through stories and songs. More than one third of the pupils reported that it was easy for them to understand the life skills presented in the stories (75-77\%) whereas $(89 \%)$ of students reported they can easily share in the program activities. only (66-67\%) of the students reported that the time was enough for practicing life skills and language learning strategies. $100 \%$ of the students assured that they learnt better with the proposed program. 


\subsection{Qualitative Data}

\subsubsection{Results of Teachers' Self-Reflection Logs}

Analyzing teachers' logs provided the researcher with some qualitative data about the challenges that they faced all through the treatment. In addition to the challenges, teachers referred to their best practices and their successes while teaching the program lessons. Moreover, it was important for the researcher to investigate if there are any differences between the two pairs of teachers (those who received training on how to use children literature in teaching life skills and those who did not). Yet, surprisingly, no clear differences between the two pairs were reflected. Throughout the experience the untrained teachers took responsibility for their own learning. They engaged in pair and individual reflective activities after each class session to identify the strengths and weaknesses of past lessons as they worked together to improve future lessons. It is observed that there is a significant change in the attitudinal approach of the teachers of both groups. They became more receptive to the problems of their students and there is an improvement in their relationship. Experience suggests that teachers need support in the form of syllabus, resource materials and time to be able to promote life skills among their primary students. Teachers were able to complete the activities within an hour and reported active student participation. Most teachers were satisfied with the small group discussions and their role as facilitators, and were confident of their ability to conduct the activities and discuss life skills. They reported some procedural difficulties pertaining to space and (large) number of students; but on the whole the teachers were satisfied with their efforts and with the teacher's guide as resource material.

\subsubsection{Students' Learning Logs and Direct Classroom Observations}

Depending on direct classroom observations and analyzing students' learning logs, the researcher noticed the direct effect of the program on students life skills represented in their comments i.e. "Oh, this is what I used to do, I have to stop it now", "I can really use this skill to please my teachers and myself", and "I've really learned a lot from my classmates about how to deal with my situation". Such feedback makes the effort put into the activity worthwhile.

\subsection{Qualitative vs. Quantitative Data}

Data Analysis of the qualitative data based on teachers' reflection log and quantitative data from the standardized measures of students' life skills and language learning strategies of both experimental groups revealed interesting contrasts in the data. In qualitative teachers' logs, data indicated that there were no significant difference between those teachers who received pre-training and those who did not. Yet, analysis of the results of the standardized measures of life skills and language learning strategies revealed that there is a difference between the performance of the two experimental groups in favor of the second experimental group whose teachers received training (except for the situation test results). A possible explanation for this disconnect between the two sources of data was that the teachers' log was restricted to certain items concerning teacher's reflection on their teaching and did not reflect on students' learning. Moreover, the researcher wonders if the teachers actually reported about their teaching experience according to what they actually did. They may have exaggerated their answers in the reflection log. Also, as mentioned previously, the untrained teachers most probably were unaware of the life skills and how to integrate such skills in their teaching, so they may have thought that they were integrating them when, in fact, they were not.

\section{Discussion and Implication of the Results}

The results obtained from the above data analysis ensure the answer to the study's main question about the effectiveness of the proposed children literature based program on the fifth primary stage students' life skills (with its four main domains: cognitive, personal, social and linguistic) and their usage of necessary language learning strategies. Finding the right story and song, using certain selection criteria, is critical. Children literature forms selection should meet certain objectives and subjective criteria. Objective criteria relate to linguistic features; subjective criteria relate to the child and his/her preferences. For example, Martin (2004) states that to choose the correct story, teacher should choose those that relate to students, the one which he feel that he can tell well. The chosen stories should have a clear, uncomplicated storyline, they should have a clear, uncomplicated storyline, and they should have repeated grammatical structures that enable children to acquire useful phrases. Hana (2010, pp. 7-8) added that story should have action, plot should be understandable to the listeners, and the events of the story should have a definite climax that leads to a conclusion that students find satisfying. Moreover, stories should exercise the imagination and encourage children to learn how to learn.

Literature based activities in the proposed program offered a break in everyday instructional routines. Telling stories about their own personal behaviors and interactions in daily life in a simple and natural way and with 
great self-confidence was one of the successes for the students themselves. Also, results proved that exposing students to a range of life experiences and problematic daily life situations through a literary work and involving them in practicing their cognitive, personal, social and linguistic skills in dealing with such situations through meaningful activities positively affected their own life skills plus enjoying what they were learning and in this way learning becomes fun. The visual and auditory components involved in the stories and songs attracted students' attention. Students maintained a high level of excitement and engagement in content and language learning. Students were very enthusiastic to learn by acting, telling and retelling, singing activities; they were concentrating all the time. This interpretation is in line with the studies conducted by a number of researchers among which are Kiran et al. (2007), Greegersen (2013), and O'dwyer (2013) who declared that life skills education involves a dynamic teaching process and that the methods used to facilitate this active involvement includes working in small groups and pairs, brainstorming, role plays, games and debates. Encouraging students to focus on details such as character's facial expressions, body gestures and vocal cues during role play activities as indicators of empathy, sharpen children's awareness of emotional needs and states in others through the use of emotional related language. Also, teachers' reflective questions promoted an understanding of reciprocal relationships between characters in the stories. All these activities positively affected students' social, personal skills and interpersonal communication life skills. This is consistent with what De Carol (1999), Reese (2002), and Al-Alami (2003) recommended. Stimulating students' reflective thinking, through filling their learning-logs, gave them the chance to personalize their learning and adapt their behaviors accordingly.

Results indicated that there were statistically significant differences between the first experimental group (whose teachers received no pre-training), and the second experimental group (whose teachers received pre-training) students' mean scores on the post administrations of the life skills measures, namely, the personal and social questionnaire and the oral interpersonal communication test and the language learning strategies questionnaire in favor of the second experimental group. This result first, highlights the extent to which students are affected by their teachers on both social and personal levels, as they see their teachers as models and respect their advices and try to behave the way teacher likes. Hence, training primary school EFL teachers on techniques and strategies for integrating life skills in their classroom teaching is a core element in the process of preparing students for actual world. EFL Teachers need to reduce the grammatical focus, which dominate their classrooms, and try to relate language to life. Children opportunities to use language as a tool for creating and sharing meanings and by scaffolding experiences to help them function "at the growing edge". Second, there was no statistically significant difference between students of both experimental groups on the life skills situation test that measures the cognitive domain. This may be attributed to the intellectual characteristics of students at this growth stage, which stresses concrete, practical learning experiences in which student integrate his own ideas and experiences naturally through problem based situations.

Moreover, involving parents in the program activities (evaluation activities) supported their children's life skills. Parental support is a powerful variable predicting student's self-confidence, personal development, social development, and linguistic development. Cripps and Zyomski (2009) and Annear and Yates (2010) assure that high levels of parental involvement positively affect students' sense of psychological well-being, especially in the areas of self-esteem and self-evaluation.

\section{Recommendations}

Based on the results of this study, the following points are recommended:

- A lot of attention and interest should be paid for enhancing students' life skills as early as possible starting from the primary stage.

- Curriculum designers may incorporate units based on short stories and songs in the EFL curricula as a way for enhancing the pupils' life skills

- Encouraging students' reflective thinking deepens the effect of the classroom activities.

- Training EFL teachers on integrating life skills in their teaching aims and designing as well as implementing interactive activities for developing them among students.

- Involving Parents in supporting classroom learning experiences is of great importance.

\section{Suggestions for Further Research}

Based on the above data, the following research studies are suggested:

- A project/ field trips based program for developing life skills of secondary school students.

- Investigating the effect of using games on developing primary students' language learning strategies. 


\section{References}

Al-Alami, S. (2003). The effectiveness of using short stories in enhancing Jordanian secondary stage students reading and writing skills (Unpublished Doctoral dissertation). Ain Shams University, Cairo, Egypt.

Annear, K. D., \& Yates, G. C. R. (2010). Restrictive and supportive parenting: Effects on children's school affect and emotional responses. The Australian Educational Researcher, 37, 63-82.

Baily, S. J., \& Deen, M. Y. (2002). Development of a web-based evaluation system: A tool for measuring life skills in youth and family programs. Family Relation, 51, 138-147.

Cripps, K., \& Zyromski, B. (2009). Adolescents' psychological well-being and perceived parental involvement: Implications for parental involvement in middle schools. Research in Middle Level Education Online, 33(4), 1-13.

De Naples, F. (2002). You can always teach, Modern Language. Association of America, 117(3), 496-498.

Dornyie, Z. (2005). Psychology of the language learner. Mahwah, New Jersy: Lawrence Erlbaum Associates, Inc.

Education Commission. (2000). Learning for life, learning through life: Reform proposals for the education system in Hong Kong. Hong Kong Special Administrative Region of the People's Republic of China: Education Commission.

Ellis, G. (2002). Tell it again, the new storytelling Handbook for primary teachers. Penguin books.

El-Naggar Zeinab, et al. (2002). SPEER: Spotlight on primary English education resources: A resource text for Egyptian primary educators, supervisors and teachers. Washington: Academy for educational Development.

Hana, N. (2010). Using storytelling technique to develop EFL listening skill. Journal of Mansoura Faculty of education, Mansoura University, 73(2), 1-33.

Hillary, C. (2012). The Development of a Sport-Based Life Skills Scale for Youth to Young Adults, 11-23 years of age (Doctoral Dissertation). UMI Dissertations Publishing.

Iowa State University Extension (ISUE). (2012). Targeting life skills model. Retrieved June 20, 2014, from http://extension.iastate.edu/4h/explore/lifeskills-cached

John, O. (2013). Pedagogical leadership for life skills in ESOL. Proceedings of the 18th TESOL Arabia Conference'Achieving Excellence through life skills education. Dubai: TESOL Arabia publications. 3-12.

Kiran, S., Seshadri, S., \& Thomas, K. (2007). Developing a life skills program for educationalits using experiential methodologies. The international journal on school disaffection, 22-27.

Linda, S. A. (2006). Assessing children literature. Anti-Defamation League, New York.

Littlewood, W. (2000). Literature in the School Foreign-Language Course. In C. J. Brumfit, \& R. A. Carter (Eds), Literature and Language Teaching. Oxford: OUP.

Maria, P. (2011). Building Identity and Understanding Diversity-Children's Literature and Traditional Literature Potential in the School Curriculum. US-China Education Review, 2, 251-262.

Martin, I. (2004). Children's literature and area studies. Retrieved May 2011, from http://www.falcon.jmu.edu/ramseyil/storydefinition.htm

Oxford, R. (2003). Language learning styles and strategies: An overview. Learning Styles \& Strategies/Oxford, $G A L A, 1-25$. Retrieved from http://web.ntpu.edu.tw/ language/workshop/read2.pdf

Pardeede, P. (2011). Using short stories to teach language skills. Journal of English Teaching, 1(1), 15-27.

Peter, S. (2011). Life Skills Development in Junior Secondary Students from Hong Kong with Specific Learning Difficulties (Doctoral Dissertation). California School of Professional Psychology, Alliant International University.

Rebecca, B. (2013). Language is a life skill, Macmillan life skills newsletter. Retrieved March 2014, from www.macmillanenglish.com/life-skills

Reese, J. D. (2002). Learning for understanding: Role of world literature. English journal, 91(5), 63-69. Database: ERIC.

Shelly, M. (2011). Life skills training through situated learning experiences: An alternative instructional model. 
International Journal of Special Education, 26(3), 1-6. http://www.internationaljournalofspecialeducation. com/articles.cfm? $=2011 \& \mathrm{v}=26 \& \mathrm{n}=3$

Spencer, K. (2004). Addressing the life skills crisis: Win-win discipline: Strategies for all discipline problems. Clemente, CA: Kagan Publishing.

Steve, K. (2013). Life skills: What they are and why we need to teach them. Macmillan life skills: Language is a life skill newsletter. Retrieved March 25, 2014, from http://www.macmillanenglish.com/life-skills

Tammy, G. (2013). Language strategies and life skills: Mirrored Goals. Proceedings of the 18th TESOL Arabia Conference: Achieving Excellence through life skills education. Dubai: TESOL Arabia publications. 13-21.

Yuen, M., Hui, E., Gysbers, N., Lau, P., Chan, R., \& Shea, P. (2007). Life skills development among junior secondary students in Hong Kong: Brief report on follow-up survey. University of Hong Kong Life Skills Development Project.

Zafeiriadou, N. (2001). Literature in the EFL classroom. Retrieved March 2014, from http://www.tesolgreece.com/nl/71/7104.html

\section{Appendix 1}

Life skills checklist

\begin{tabular}{lll}
\hline Skills & $\begin{array}{l}\text { Very } \\
\text { important }\end{array}$ & Important Less \\
& important \\
\hline
\end{tabular}

Cognitive skills "learning to know"

1 Critical thinking \& problem solving:

- Examine the offered evidence and reasoning.

- Draw specific conclusions from a set of general observations

- Investigate all possible solutions to a problem, weighting the pros and cons

2

\section{Decision making:}

- Make choices based on a critical analysis of specific contexts

(e.g. food choice based on their effect on health)

- Determine the most efficient course of action for completing a

task

- Respond to peer pressure appropriately

- Schedule, plan and prioritize daily $\&$ future activities

\section{Creativity $\&$ innovation:}

- Generate variety of new ideas (fluency)

- Shift perspective easily (flexibility)

- Look beyond direct experience

- Conceive of something new (originality)

Personal skills "learning to be"

1 Increasing internal locus of control:

- Self-awareness (awareness of rights, values, attitudes, strengths, weaknesses)

- Self esteem/ confidence

- Regulate one's own feelings, desires and behaviors

2 Managing emotions:

- Being aware of how emotions influence behavior

- Respond to emotions appropriately

- Anger management

Managing stress: 
- Deal with stressful, unexpected or unmanageable situations

- Use relaxation techniques that help in controlling stress and relaxing.
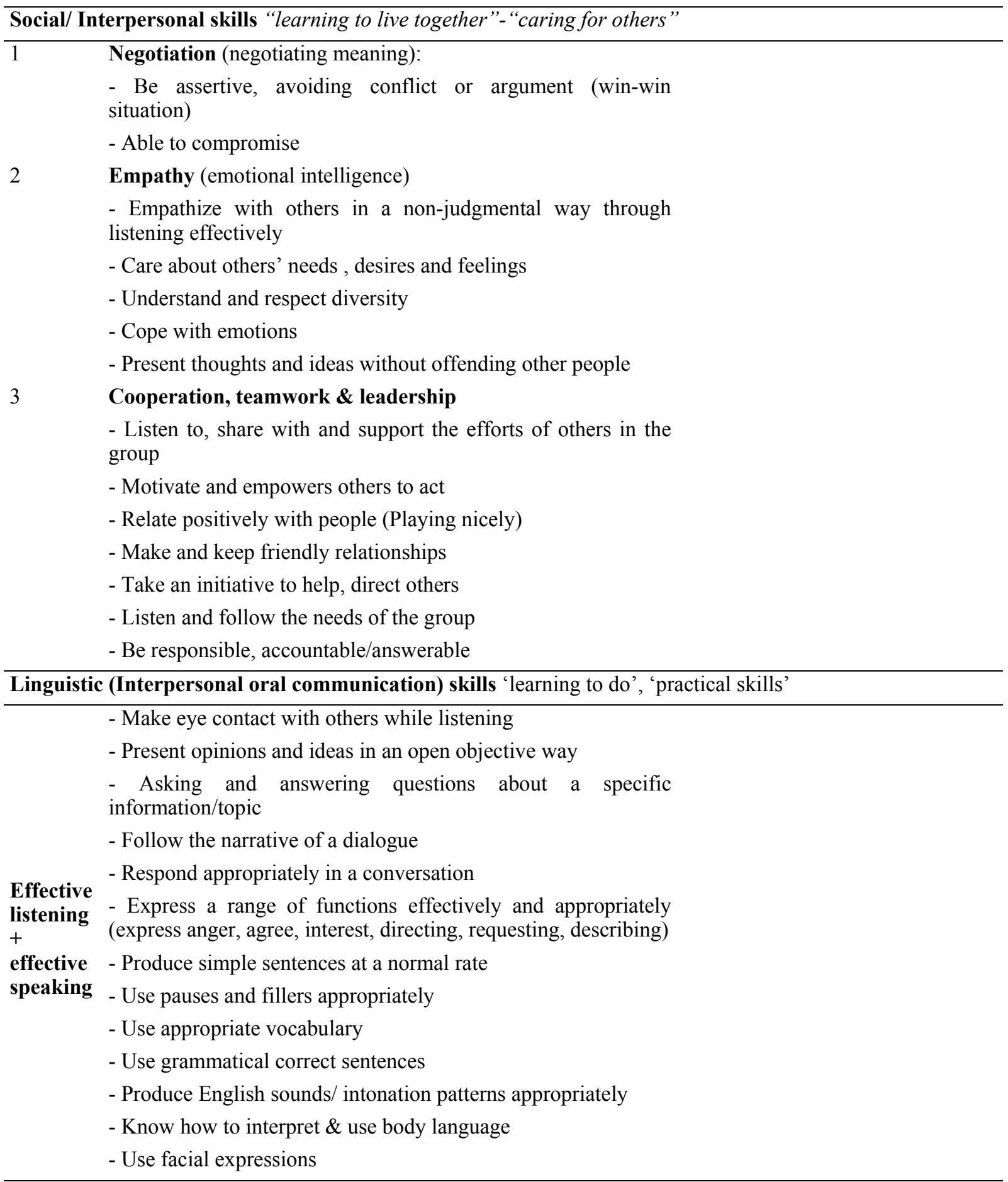

\section{Copyrights}

Copyright for this article is retained by the author(s), with first publication rights granted to the journal.

This is an open-access article distributed under the terms and conditions of the Creative Commons Attribution license (http://creativecommons.org/licenses/by/3.0/). 